\title{
Determination of Caffeic Acid in Wine Samples Based on the Electrochemical Reduction of Graphene Oxide Modified Screen Printed Carbon Electrode
}

\author{
Murugan Velmurugan, Paramasivam Balasubramanian, Shen-Ming Chen* \\ Department of Chemical Engineering and Biotechnology, National Taipei University of Technology, \\ Taipei 106, Taiwan, ROC \\ *E-mail: smchen78@ms15.hinet.net
}

doi: $10.20964 / 2017.05 .01$

Received: 28 December 2016 / Accepted: 24 February 2017 / Published: 12 April 2017

\begin{abstract}
An electrochemically reduced graphene oxide was produced by cyclic voltammetric technique and ERGO modified electrode used a new sensor for determination of caffeic acid (CA). The reduced graphene oxide were characterized by Fourier transform infrared spectroscopy (FTIR), Scanning electron microscope (SEM), Raman spectra and cyclic voltammetry (CV). The results reveals electrochemically reduced graphene oxygen content could be decreased significantly. The electrochemical sensor properties examined by cyclic voltammetry and differential pulse voltammetry (DPV). Our proposed sensor ERGO/SPCE exhibited tremendous electrochemically activity towards oxidation of the CA and enhanced current response compared with bare SPCE and GO/SPCE. The wide linear range from 0.2 to $2100 \mu \mathrm{M}$ and limit of detection $0.064 \mu \mathrm{M}$ were obtained. The proposed sensor ERGO/SPCE was successfully applied to detection of caffeic acid in wine samples.
\end{abstract}

Keywords: Caffeic acid; graphene oxide; Electrochemical reduction; screen printed carbon electrode; Wine samples.

\section{FULL TEXT}

(C) 2017 The Authors. Published by ESG (www.electrochemsci.org). This article is an open access article distributed under the terms and conditions of the Creative Commons Attribution license (http://creativecommons.org/licenses/by/4.0/). 